\title{
Declaring Brain Death on ECMO
}

\author{
Kristin J. Kreitler, CRNP ${ }^{1}$; Nicholas C. Cavarocchi, MD ${ }^{1}$; Hitoshi Hirose, MD, $\mathrm{PhD}^{1}$, \\ Sharon West, RN 2; Richard Hasz, PhD 2; Michelle L. Ghobrial, MD; \\ Rodney D. Bell, MD ${ }^{3}$ \\ ${ }^{1}$ Department of Surgery, Thomas Jefferson University, Philadelphia, PA \\ ${ }^{2}$ Gift of Life Donor Program, Philadelphia, PA \\ ${ }^{3}$ Department of Neurology, Thomas Jefferson University, Philadelphia, PA
}

\section{Key Words}

ECMO, brain death, apnea test, ancillary test, organ donation

This abstract was presented at American Transplant Conference, Philadelphia, PA, on May 2, 2015

\begin{abstract}
Purpose: Accumulating evidence suggests that organs from ECMO patients can be safely transplanted after a declaration of cardiac or brain death. However, making a diagnosis of brain death while a patient is on ECMO poses unique challenges and limited literature exists. We sought to describe the practice variations involved with declaring patients brain dead on ECMO by reviewing charts from our local organ procurement organization.
\end{abstract}

Methods: After institutional review board approval, a retrospective chart review from our local organ procurement organization was performed to identify patients declared brain dead on ECMO who became organ donors. Between 1995 and 2014, we identified 26 patients on ECMO who donated organs after being diagnosed with brain death. Demographics, causes of death, clinical and ancillary studies used to pronounce brain death were recorded from charts.

Results: All patients underwent one to two clinical exams as the initial step in the declaration of brain death. In addition to clinical examination, $15(58 \%)$ of the patients underwent apnea testing, and of those, seven (47\%) also had at least one ancillary test performed. Apnea testing was not utilized in $11(42 \%)$ of the patients, and of those, nine $(82 \%)$ had one or more ancillary tests performed to confirm brain death. Two $(18 \%)$ patients underwent clinical examination only. Seventy-five percent of patients from 1995 - 2008 underwent apnea testing compared with only $50 \%$ of patients from 2009 to 2014.

Conclusions: This study demonstrated the variability of practice patterns in the declaration of brain death for patients on ECMO over time and the lack of understanding of the $\mathrm{CO} 2$ physiology on ECMO. Additional studies are needed to devise a national standardized protocol to declare brain death on ECMO.

\section{INTRODUCTION}

ECMO is becoming a widely used therapy for the supportive care of patients with acute cardiac and respiratory failure. From 2006 to 2011, the utilization of ECMO in adults in the United States has increased by $433 \% .{ }^{1}$ According to the Extracorporeal Life Support Organization Registry, ${ }^{2}$ pediatric respiratory ECMO has also grown from approximately 200 cases per year from 1993 to 2004 to 331-448 cases per year from 2008 to 2012. This increase may be due to an enhanced understanding of the physiology of ECMO, as well as improvement in technology that occurred in the late 2000's. 3,4 As technology has improved, the survival rate of patients supported by ECMO has increased. ${ }^{5}$

As with many life-saving therapies, complications can arise. Neurological injuries can result on ECMO, although often times these injuries occur from other causes, such as hypoxic brain injury before the initiation of ECMO. The incidence of reported neurological complications in patients on ECMO varies from 13 to $37 \% .^{6-10}$ When a neurological injury does occur in the patient on ECMO, it often results in poor outcomes, and sometimes brain death. ${ }^{9,11,12}$ Patients who have been pronounced brain dead on ECMO have gone on to become viable organ donors, which is an important advantage in the setting of rapidly growing transplant lists. ${ }^{13,14}$

One component in the diagnosis of brain death, the apnea test, is technically challenging in the setting of ECMO. Limited literature describes apnea testing and declaration of brain death in adult and pediatric ECMO patients. ${ }^{15-19}$ Several case reports have only been published in the past three to four years, but prior to that, no literature was available regarding how to pronounce brain death on ECMO. The purpose of this paper is to describe the clinical practice variations, ancillary testing and trends with declaring patients brain dead on ECMO and to highlight the need for the development of consensus guidelines to assist clinicians with the accurate diagnosis of brain death in this specific patient population.

\section{METHODS}

After obtaining institutional review board approval (\#11D617), our local organ procurement organization (OPO) database was retrospectively analyzed to identify patients who had been declared brain dead on ECMO and went on to become organ donors. Our OPO partners with 130 acute care hospitals in the Delaware Valley region, which includes 


\begin{tabular}{|c|c|c|c|c|c|c|c|}
\hline Patient & Year & $\begin{array}{l}\text { Clinical } \\
\text { Exam (\#) }\end{array}$ & $\begin{array}{c}\text { Apnea } \\
\text { test }\end{array}$ & EEG & CBF & $\mathrm{TCD}$ & Other \\
\hline 1 & 1995 & $x x$ & $x$ & $x$ & & & \\
\hline 2 & 1997 & $x$ & & $x$ & & & \\
\hline 3 & 2001 & $x x$ & $x$ & & & & \\
\hline 4 & 2006 & $x x$ & $x$ & & & & \\
\hline 5 & 2007 & $x x$ & $x$ & & & & \\
\hline 6 & 2007 & $x$ & $x$ & & $x$ & & \\
\hline 7 & 2008 & $x x$ & $x$ & $x$ & & & \\
\hline 8 & 2008 & $x x$ & & & & & \\
\hline 9 & 2009 & $x x$ & & $x$ & & $x$ & \\
\hline 10 & 2009 & $x x$ & $x$ & $x$ & & & \\
\hline 11 & 2010 & $x x$ & $x$ & & & & \\
\hline 12 & 2011 & $x x$ & $x$ & & $x$ & & \\
\hline 13 & 2012 & $x x$ & $x$ & & & & \\
\hline 14 & 2012 & $x x$ & 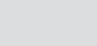 & & & & $x$ \\
\hline 15 & 2012 & $x x$ & $x$ & & & & \\
\hline 16 & 2013 & $x x$ & $x$ & & & & \\
\hline 17 & 2013 & $x x$ & & & & & \\
\hline 18 & 2013 & $x x$ & & $x$ & & & \\
\hline 19 & 2013 & $x x$ & & & $x$ & & \\
\hline 20 & 2013 & $x$ & . & & $x$ & & \\
\hline 21 & 2013 & $x x$ & $x$ & & $x$ & & \\
\hline 22 & 2014 & $x x$ & $x$ & $x$ & & $x$ & \\
\hline 23 & 2014 & $x$ & & & $x$ & & \\
\hline 24 & 2014 & $x x$ & & & $x$ & $x$ & \\
\hline 25 & 2014 & $x x$ & $x$ & & & & \\
\hline 26 & 2014 & $x x$ & & & & & $x$ \\
\hline
\end{tabular}

CBF: Cerebral blood flow nuclear study; EEG: Electro-encephalography; TCD: Trans-cranial Doppler. Other studies include CT scan and CT angiography.

Pennsylvania, Delaware, and New Jersey, and is the largest OPO in the United States. ${ }^{20}$ The patients included in this study were from various hospitals within the region. Patients were excluded from the study if they were on another form of mechanical circulatory support or if they were not on ECMO at the time of brain death diagnosis. Only patients on ECMO who had been diagnosed with brain death were included in the study, therefore patients with a diagnosis of cardiac death were excluded. Once patients were identified, we reviewed the medical records from the OPO, focusing on the methods used to diagnosis brain death. The original hospital records for each patient were not available.

\section{RESULTS}

Twenty-six patients were retrospectively identified that donated organs after brain death was determined while on ECMO between October 1995 and July 2014. This cohort consisted of 13 male and 13 female, with a mean age of $27+/-22$ years. The median length of days on
ECMO before being pronounced brain dead was 3 days. Twenty-two $(85 \%)$ of the patients underwent clinical examination by two separate clinicians at two separate times as the initial step in the declaration of brain death, whereas $4(15 \%)$ patients only had one clinical examination. In addition to clinical examination, 15 (58\%) of the patients underwent apnea testing. Among those patients, 7 (47\%) also had at least one ancillary test performed to confirm the diagnoses of brain death. Of the 15-apnea tests that were performed, only $7(47 \%)$ of them would actually be considered confirmatory based on American Academy of Neurology guidelines. ${ }^{21}$ The apnea tests that were not confirmatory were due to the carbon dioxide levels not rising appropriately; ${ }^{3}$ patients becoming hypoxic or unstable to continue the test; ${ }^{3}$ due to the discretion of the neurologist who did not feel that an apnea test performed with a patient on ECMO was reliable. ${ }^{2}$ Ancillary testing was performed in $75 \%(6 / 8)$ of the patients with non-confirmatory or undetermined apnea test. Apnea testing was not utilized in $11(42 \%)$ of the patients, and of those patients, nine $(82 \%)$ had at least one ancillary test performed to confirm the diagnosis of brain death (Figure 1). Two (18\%) patients underwent clinical examination only. Seventy-five percent of patients from 1995 through 2008 underwent apnea testing compared with only $50 \%$ of patients from 2009 to 2014 (Figure 2).

In addition to apnea testing, multiple ancillary tests were used to assist with the diagnosis of brain death. These ancillary tests included electroencephalography (EEG), cerebral blood flow nuclear study (CBF), and trans-cranial Doppler (TCD). Two patients underwent $C T$ angiogram of the head or CT of the head to ensure the diagnosis of brain death.

When apnea testing was not utilized in the determination of brain death or when ancillary studies were performed in addition to apnea testing, documented rationales were: "neurology's request", "patient instability" (2), "drug intoxication", ${ }^{1}$ and "ECMO".7 All cases in which ECMO was documented as the reason for not performing an apnea test occurred after 2008. 


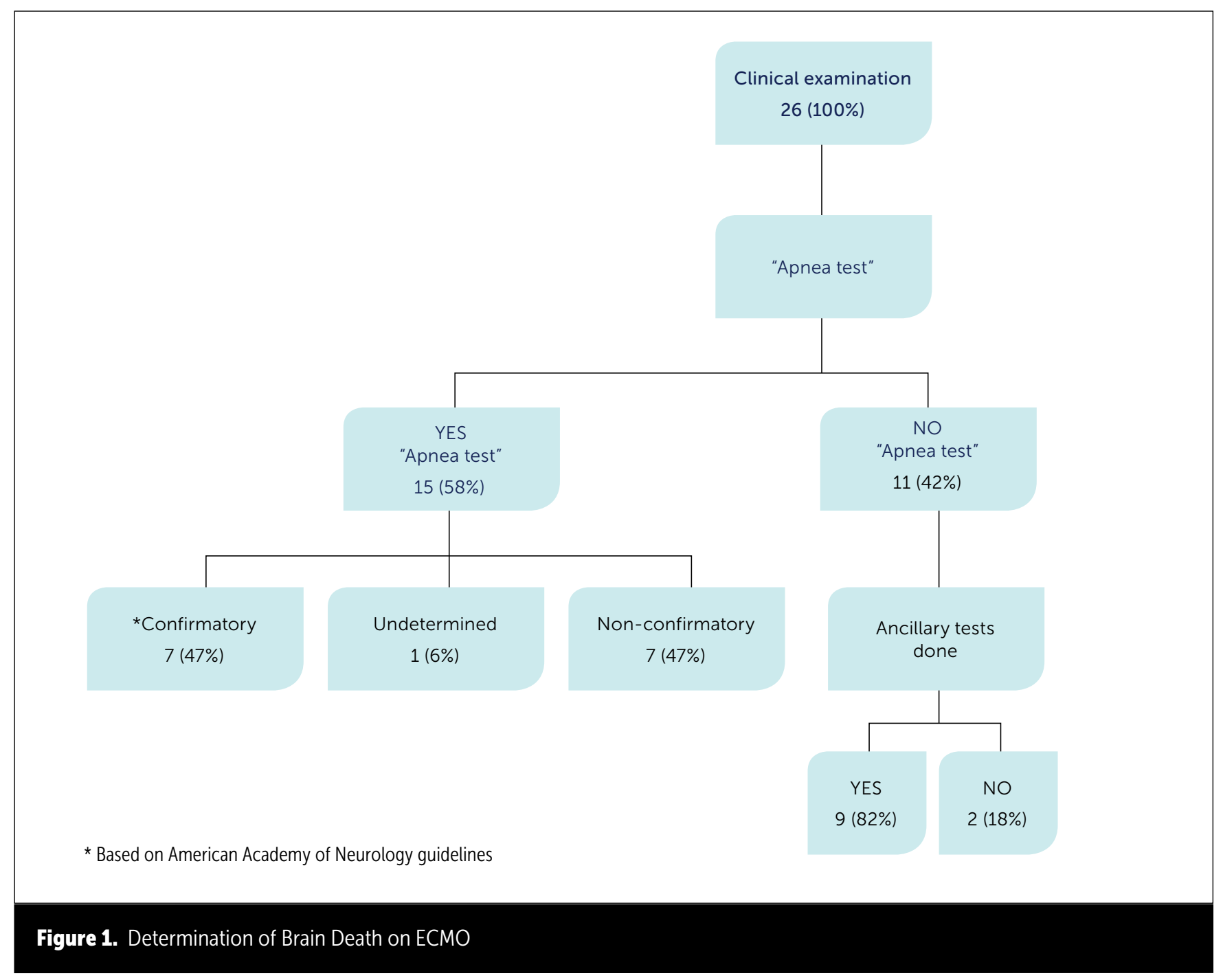

\section{DISCUSSION}

This study represents the largest reported cohort of patients who were declared brain dead on ECMO and the clinical steps taken to confirm the diagnosis of brain death. This data not only confirmed the variations in clinical practices and use of ancillary testing, it highlighted uncertainties regarding how to confirm brain death in this specific patient population. Seven of the cases in this study documented ECMO as either the reason for not performing an apnea test or reason for performing confirmatory ancillary testing in addition to the apnea test. In five other cases, an apnea test was not performed without clear documentation as to why the apnea test was not done. It appears that many clinicians in these scenarios recognized the challenges and limitations of apnea testing in ECMO patients. Review of the data also revealed that the results of three apnea tests may have been reported incorrectly by the performing institution, further highlighting evidence of how difficult it can be to perform and interpret the apnea test in these patients.

Although apnea testing to confirm brain death in ECMO patients has been reported, the literature is limited to very few case reports and those case reports all suggest different processes for performing an apnea test on a patient on ECMO..$^{15-19}$ Similarly in this study, five charts did provide documentation as to how the apnea test was performed and all tests were performed differently. For example, our research showed one apnea test was performed with the sweep (ventilation control on ECMO) off, while another was performed with the sweep at minimum. In addition to the various procedures taken with regard to the sweep, the apnea tests also varied in regards to whether or not the patient remained on the ventilator with pressure support settings or was taken off the ventilator completely, what the ECMO flow rate was placed at, and the times in which the ECMO settings were 
adjusted before making a decision about whether the test was positive or negative. Muralidharan et $a_{1}, 22$ suggested a procedure for performing an apnea test on ECMO, but made note of three cases in which patients on ECMO were found to have lost all brainstem reflexes, but apnea testing was not performed because it was deemed "difficult."

According to the guidelines from the American Academy of Neurology, ${ }^{21}$ after meeting all of the prerequisites to proceed with brain death testing, a clinical examination should be performed, and if that examination is consistent with brain death, then apnea testing should occur. The procedure for the apnea test is as follows:21 1) Adjust vasopressors to a systolic blood pressure $>/=100 \mathrm{~mm} \mathrm{Hg}$, 2) Pre-oxygenate for at least 10 minutes with $100 \%$ oxygen to a $\mathrm{PaO}_{2}>200 \mathrm{~mm}$ $\mathrm{Hg}$, 3) Reduce ventilation frequency to 10 breaths per minute to eucapnia, 4) Reduce positive end-expiratory pressure to $5 \mathrm{~cm} \mathrm{H}_{2} \mathrm{O}$, 5) If pulse oximetry oxygen saturation remains $>95 \%$, obtain a baseline blood gas, 6) Disconnect the patient from the ventilator, 7) Preserve oxygenation by placing an insufflation catheter through the endotracheal tube and close to the level of the carina and delivery $100 \%$ oxygen at $6 \mathrm{~L} / \mathrm{min}, 8$ ) Look closely for respiratory movements for 8-10 minutes, 9) Abort if systolic blood pressure decreases to $<90 \mathrm{~mm} \mathrm{Hg}$ or if oxygen saturation measured by pulse oximetry is $<85 \%$ for $>30$ seconds, 10) If no respiratory drive is observed, repeat blood gas after approximately 8 minutes, 11) If respiratory movements are absent and arterial $\mathrm{PCO}_{2}$ is $>/=60 \mathrm{~mm} \mathrm{Hg}$ or $20 \mathrm{~mm} \mathrm{Hg}$ over a baseline normal arterial $\mathrm{PCO}_{2}$, the apnea test result is positive, and 12) If the test is inconclusive but the patient is hemodynamically stable during the procedure, it may be repeated for a longer period of time (10-15 minutes) after the patient is again adequately pre-oxygenated.

This apnea test presented multiple procedural challenges for the patient on ECMO. $\mathrm{A} \mathrm{PaO}_{2}$ of $>200$ may not be obtainable in patients on ECMO by placing the $E C M O \mathrm{FiO}_{2}$ to $100 \%$, since the majority of patients are in acute respiratory distress syndrome or pulmonary edema. Secondly, patients on veno-arterial ECMO often have

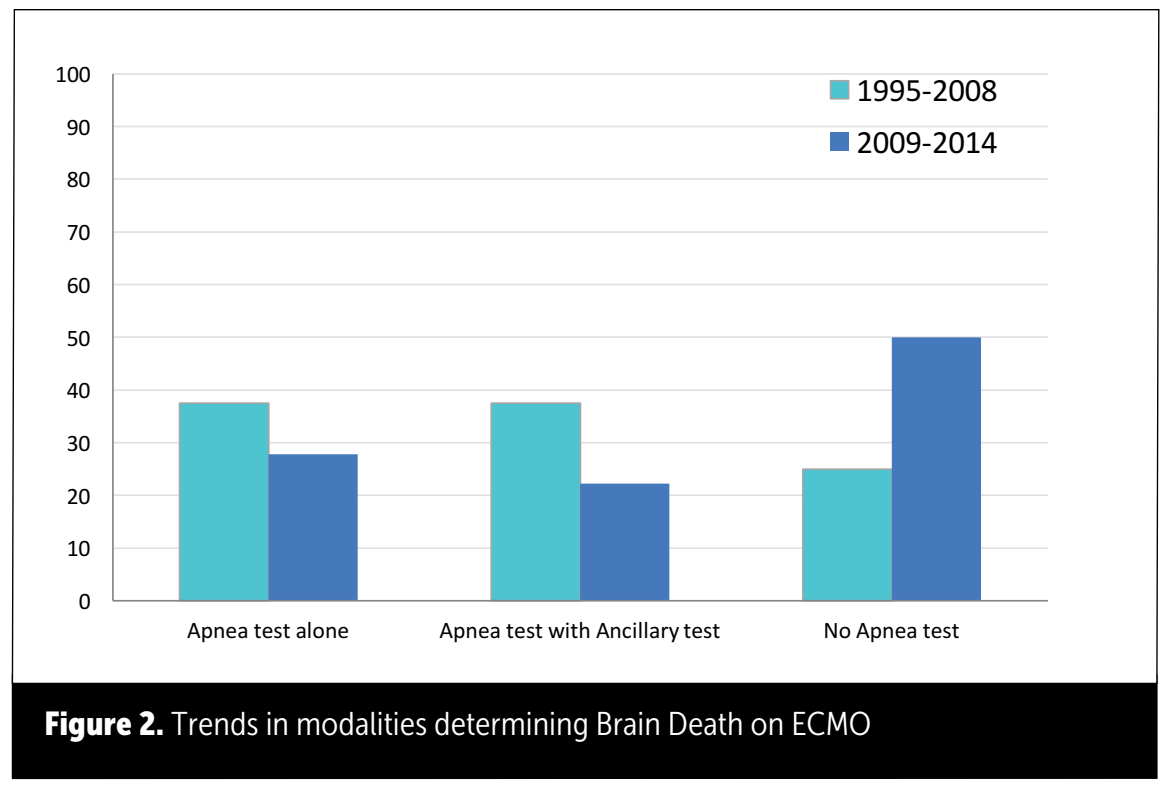

minimal pulsatility; therefore, they do not have a systolic blood pressure, only a mean arterial pressure. Furthermore, it has been demonstrated that even at a minimum gas sweep flow (less than $1 \mathrm{~L})$, a fraction of inspired oxygen of $100 \%$, and minimum ECMO flow, carbon dioxide can still be effectively cleared by the oxygenator. The Maquet Quadrox oxygenator is very efficient at $\mathrm{CO}_{2}$ removal and any sweep gas will effectively lower the $\mathrm{CO}_{2}$. Therefore, in order to demonstrate a rise in $\mathrm{CO}_{2}$ from an apneic patient, the sweep must be turned significantly down or off, and doing this will stop the oxygenation of the blood through the ECMO oxygenator.

According to the American Academy of Neurology ${ }^{21}$ guidelines, if an apnea test is aborted or inconclusive, ancillary testing should be performed. Beginning in 2009 , we noted a trend in which apnea tests were less often utilized in the diagnosis of brain death for patients on ECMO (Figure 2). This was approximately the same time in which newer generations of ECMO circuits were being used. Ancillary tests are generally well supported in the literature to confirm a diagnosis of brain death in the general population; they have not been extensively studied or reported in the ECMO population. The alterations in blood flow patterns, oxygenation, and ventilation that are created by ECMO affect the usefulness of ancillary tests used for the diagnosis of brain death on ECMO.

This study demonstrates variations in practices in brain death declaration, especially in regards to apnea testing, in patients on ECMO. Standardization is urgently needed to assure consistent, accurate brain death pronouncement in order to facilitate organ procurement when appropriate. We hope future brain death guidelines incorporate the ECMO population

This study was limited to the data from a single local OPO, although this OPO is the largest in the United States. Additional limitations include that the data on the studied patients were limited by what the OPO collected from various hospitals, and because we did not have access to the full medical records, information such as patient history (primary cardiac failure vs. primary respiratory failure), the type of ECMO (veno-arterial vs. veno-venous), and details of the apnea test and clinical examination was missing, incomplete, or difficult to interpret. The primary medical record review was not performed due to strict HIPAA violations. Also this study was limited to patients who were evaluated for organ donation and went on to become organ donors. Individuals who were evaluated for donation but were rejected were also unable to be included in this study. 


\section{CONCLUSION}

Due to the substantial and continued increase in the utilization of ECMO for cardiac and respiratory support, the ethical and legal implications involved in the pronunciation of brain death, the growing number of patients on the organ waiting list, and the recent evidence that organs from ECMO donors have similar outcomes as other organs from other donors, it is imperative that consensus guidelines are developed to guide clinicians in the accurate diagnosis of brain death in patients receiving ECMO. Future research should focus on the best way to perform an apnea test with specific recommendations on ECMO settings, as well as the reliability of ancillary testing, such as CBF, TCD or EEG, when an appropriate apnea test cannot be performed.

\section{REFERENCES}

1. Sauer CM, Yuh DD, Bonde P. Extracorporeal membrane oxygenation (ECMO) use has increased by $433 \%$ in adults in the United States from 2006 to 2011. ASAIO J 2015: 61:31-36.

2. Paden ML, Rycus PT, Thiagarajan RR. Update and outcomes in extracorporeal life support. Semin Perinatol 2014; 38:65-70.

3. Toomasian JM, Schreiner RJ, Meyer DE, Schmidt ME, Hagan SE, Griffith GW, et al. A polymethylpentene fiber gas exchanger for long-term extracorporeal life support. ASAIO J 2005; 51:390-397.

4. Sidebotham D, McGeorge A, McGuinness $S$, Edwards M, Wilcox T, Beca J. Emerging technology review. J Cardiothorac Vasc Anesth 2010; 24:164-172.

5. Paden ML, Conrad SA, Rycus PT, Thiagarajan RR. Extracorporeal life support organization registry report 2012. ASAIO J 2013; 59:202210.
6. Chengi $\mathrm{R}$, Hachamovitch $\mathrm{R}$, Kittleson $\mathrm{M}$, et al. Complications of extracorporeal membrane oxygenation for treatment of cardiogenic shock and cardiac arrest: a meta-analysis of 1,866 adult patients. Ann Thorac Surg 2014; 97:610-616

7. Wang J, Han J, Yixin J, et al. Early and intermediate results of rescue extracorporeal membrane oxygenation in adult cardiogenic shock. Ann Thorac Surg 2009; 88:1897-1904.

8. Cengiz P, Seidel K, Rycus P, Brogan TV, Roberts JS. Central nervous system complications during pediatric extracorporeal life support: incidence and risk factors. Crit Care Med 2005; 33:2817-2824

9. Barrett CS, Bratton SL, Salvin JW, Laussen PC, Rycus PT, Thiagarajan RR. Neurological injury after extracorporeal membrane oxygenation use to aid pediatric cardiopulmonary resuscitation. Pediatr Crit Care Med 2009; 10:445-451

10. Lidegran MK, Mosskin M, Ringertz HG, Frenckner BP, Linden VB. Cranial CT for diagnosis of intracranial complications in adult and pediatric patients during ECMO: clinical benefits in diagnosis and treatment. Acad Radiol 2007; 14:62-71.

11. Brogan TV, Thiagarajan RR, Rycus PT, Bartlett $\mathrm{RH}$, Bratton SL. Extracorporeal membrane oxygenation in adults with severe respiratory failure: a multi-center database. Intensive Care Med 2009; 35:2105-2114.

12. Thiagarajan RR, Brogan TV, Scheurer MA, Laussen PC, Rycus PT, Bratton SL. Extracorporeal membrane oxygenation to support cardiopulmonary resuscitation in adults. Ann Thorac Surg 2009; 87:778-785.

13. Carter TI, Bodzin AS, Hirose $\mathrm{H}$, et al. Outcome of organs procured from donors on extracorporeal membrane oxygenation support: an analysis of kidney and liver allograft data. Clin Transplant 2014; 28:816-820.

14. Chen CL, Wu ST, Kao CC, Cha TL, Lee CY, Tang, SH. Short-term result of renal transplantation using extracorporeal membrane oxygenation-supported brain-dead donors. Transplant Proc 2014; 46:1061-1063.
15. Hoskote SS, Fugate JE, Wijdicks, E. Performance of an apnea test for brain death determination in a patient receiving venoarterial extracorporeal membrane oxygenation. $\mathrm{J}$ Cardiothorac Vasc Anesth 2014; 28:10391041.

16. Smilevitch, $\mathrm{P}$, Lonjaret, L, Fourcade, $\mathrm{O}$, Geeraerts T. Apnea test for brain death determination in a patient on extracorporeal membrane oxygenation. Neurocrit Care 2013; 19:215-217.

17. Goswami S, Evans A, Das B, Prager K, Sladen RN, Wagener $G$. Determination of brain death by apnea test adapted to extracorporeal cardiopulmonary resuscitation. J Cardiothorac Vasc Anesth 2013; 27:312-314.

18. Shah V, Lazaridis, C. Apnea testing on extracorporeal membrane oxygenation: case report and literature review. J Crit Care Published Online: April 07, 2015, http://dx.doi. org/10.1016/j.jcrc.2015.03.028.

19. Jarrah RJ, Ajizian SJ, Agarwal S, Copus SC, Nakagawa, TA. Developing a standard method for apnea testing in the determination of brain death for patients on Venoarterial extracorporeal membrane oxygenation: a pediatric case series. Pediatr Crit Care Med 2014; 15:e38-43.

20. Available from web site: www.donors1.org.

21. Wijdicks E, Varelas PN, Gronseth GS, Greer DM. Evidence-based guideline update: determining brain death in adults: report of the Quality Standards Subcommittee of the American Academy of Neurology. Neurology 2010 Jun; 74:1911-1918.

22. Muralidharan R, Mateen FJ, Shinohara RT, Schears GJ, Wijdicks E. The challenges with brain death determination in adult patients on extracorporeal membrane oxygenation. Neurocit Care 2011; 14:423-426.

\section{Corresponding Author}

\section{Hitoshi Hirose, MD}

Department of Surgery

Thomas Jefferson University Hospital 1025 Walnut Street, Room 605,

Philadelphia, PA 19107

P: 215-955-5654

F: 215-955-6010

E: Hitoshi.Hirose@jefferson.edu

\section{Disclosure}

None of the listed authors have conflict of interest regarding this paper. 